\title{
THE LESSONS OF COUNTERPOINT
}

\author{
WOLFGANGERNST'S MEDIAARCHAEOLOGY \\ AND TELEVISION ARCHIVERESEARCH
}

\author{
Ken Griffin \\ Centre for Media Research \\ University of Ulster \\ Cromore Road, Coleraine \\ BT52 1SA \\ United Kingdom \\ k.qriffin1@ulster.ac.uk
}

\begin{abstract}
The work of German scholar Wolfgang Ernst has become increasingly influential within media archaeology. Ernst has sought to define a border between the field and traditional media history, arguing that media archaeologists should focus on the study of technological artefacts and processes. He places significant stress on the importance of media archives yet his approach to such institutions is primarily theoretical. Meanwhile, the theoretical basis for some types of media archive research is somewhat lacking. This raises the possibility of whether cross-pollination between media archaeology and these fields might prove mutually beneficial. This paper examines aspects of Ernst's writings alongside material from a recent archival project focused on a Northern Irish television series to provide an overview of the possibilities.
\end{abstract}

Keywords: media archaeology, Wolfgang Ernst, Northern Ireland, missing programmes, archival studies, Counterpoint, Ulster Television (UTV)

\section{Introduction}

Media archaeology has been promoted as an alternative to conventional media history over the past two decades. The field emerged due to discontent among some scholars about the methodologies utilised by traditional media historians. Media archaeologists became concerned about the exclusionary nature of the accounts produced by such historians. For instance, Klutinberg argued that media history marginalised failure and the contribution of minor players through its "implicit construction of a unitary narrative of progress." In the more strident critiques, historians were even accused of malpractice: Huhtamo and Parikka suggested that their accounts exhibited "negligence and ideological bias." One recurrent theme across these critiques was the idea that media historians are "not empirical enough and [need] to get closer to the materiality" of media artefacts. ${ }^{3}$

1 Eric Kluitenberg, 'On The Archaeology of Imagery Media' in Erkki Huhtamo and Jussi Parikka, eds, Media Archaeology: Approaches, Applications, and Implications, University of California Press, 2011, p. 51.

2 Erkki Huhtamo and Jussi Parikka, 'Introduction: An Archaeology of Media Archaeology' in Erkki Huhtamo and Jussi Parikka, eds., Media Archaeology: Approaches, Applications, and Implications, University of California Press, 2011, p. 3.

3 Michael Goddard, 'Opening up the back boxes: Media archaeology, 'anarchaeology' and media materiality' in New Media and Society. Published online before print April 28, 2014, 2. 
Such arguments have significant implications but media archaeology's ability to establish itself with media studies has generally been impeded by its roots as an oppositional movement against traditional media history. The field lacks agreed principles and methodologies. It is hard to disagree with Natale's assessment that "different authors who have been working under this umbrella have developed substantially different versions of it." ${ }^{4}$ Some types of media archaeology are scarcely discernible from media history: Huhtamo studies topos, stereotypical formulae repeatedly evoked within the media, such as the idea that little people live in machines, ${ }^{5}$ using a familiar content analysis methodology. At the other extreme, the discipline skirts the boundaries of fiction with scholars examining imaginary media alongside artists and sci-fi writers. ${ }^{6}$ In many respects, the only attribute that unites such diverse work is a highly oppositional stance to traditional media histories.

While some media archaeologists view this situation as providing the field with an attractive fluidity, others have suggested that its potential has been restricted by the "vague and ambiguous" manner in which its leading scholars have defined it. Goddard even remarks that Parikka's volume What Is Media Archaeology? (2012) complicated matters rather than clarifying them by identifying key themes before negating them by stating that these "are not exhaustive in any way."

\section{Ernst's Approach to Media Archaeology}

This confusion about the basis of media archaeology may account for the emergence of Wolfgang Ernst, Professor of Media Studies at Berlin's Humboldt University, as an influential figure within the field. Through his writings, Ernst has consistently sought to define the boundary between traditional media history and media archaeology. Although his work remains quite theoretical, certain key themes which potentially provide the basis for engagement with media archival research are clearly evident. The author shall discuss them in relation to his own field of television studies.

On a fundamental level, Ernst shares a common cause with television historians engaged in archival research such as Jacobs, ${ }^{9}$ Holmes ${ }^{10}$ and Johnston ${ }^{11}$ through his focus on using overlooked source material to address the gaps in prior media histories. There are, however, significant divergences between their approaches. Television historians have focused largely on analysing the contents of forgotten material held by broadcasters in their written archives.

Meanwhile, Ernst's primary concern is on technical media: the technologies underpinning its production and consumption. Within a television environment, this might, for example, include a broadcaster's videotape library and its associated equipment. He is dismissive of content analysis to the extent of arguing that media archaeologists should not examine technical media for its "mass-media content." 12 The reasons for this stance are largely beyond the scope of this paper but reflect his desire to transform the study of media into an empirical scientific discipline similar to mathematics, where historians can obtain objective knowledge through scientific observation. Ernst views content analysis as incompatible with this vision, possibly due to its perceived links with narrative creation, which is an inherently subjective process.

4 Simone Natale, 'Understanding Media Archaeology' in Canadian Journal of Communication, Vol. 37(3), 2012, p. 524.

5 Erkki Huhtamo, 'Dismantling the Fairy Engine: Media Archaeology as Topos Study' in Erkki Huhtamo and Jussi Parikka, eds, Media Archaeology: Approaches, Applications, and Implications, University of California Press, 2011, p. 27-8.

6 For example, see Eric Kluitenberg, ed., The Book of Imaginary Media, 2006, Nai Publishers.

7 Natale, 2012, p. 523.

8 Parikka, 2012 cited Goddard, 2014, p. 2.

9 Jason Jacobs, The Intimate Screen: Early British Television Drama, 2000, Oxford University Press.

10 Su Holmes, "'An ... Unmarried Mother Sat in a Wing-Backed Chair on TV Last Night ...": BBC Television Asks Is This Your Problem? (1955 - 1957)' in Television and New Media. Vol. 9(3), 2008, p. 175-196.

11 Derek Johnston, 'Experimental moments: R.U.R. and the birth of British science fiction' in Science Fiction Film \& Television, Vol. 2(2), 2009, p. 251-268.

12 Wolfgang Ernst, 'Media Archaeography: Method and Machine versus History and Narrative of Media' in Erkki Huhtamo and Jussi Parikka, eds, Media Archaeology: Approaches, Applications, and Implications, 2011, University of California Press, 2011, p. 240. 
As an alternative, Ernst suggests that technical media can be approached as acts of archaeography, inscriptions which are "not human products but rather expressions of the machines themselves." ${ }^{13}$ From this perspective, videotape is the archetypical archaeographical medium: its inscriptions are stored as magnetic signals, which are written and manipulated with limited human intervention. Ernst's interest in the issues of inscription seems inspired by the gap between the recording capabilities of technical media and their intended use by humans. As a result, media often contain extraneous material, commonly known as 'noise' which exists "outside our human intentions or signifying structures." ${ }^{14}$ Ernst suggests that this phenomenon means that technical media are "active archaeologists of data." From a more practical perspective, studying this noise is an important part of media archaeology and Ernst argues that, for example, the field's engagement with radio should involve "listening to the noise of the transmitting system itself." 15

The divergence in methodological approaches to archival media adopted by Ernst to those generally utilised within television history are significant yet complementary. Both offer a dimension that the other lacks. An Ernstian media archaeology provides a rigorous technical focus rarely exhibited with historical studies of television. Meanwhile, the type of content analysis utilised within television studies (and many other offshoots of media studies) might provide media archaeologists, despite Ernst's protestations, with a useful insight into the purposes for which various technologies were utilised by media producers. From a broader perspective, its focus on socioeconomic and cultural questions might help explore the issues concerning the relationship between media and culture raised by Ernst within his works on media archaeology. Ernst argues that technical media are autonomous from culture and possess a level of agency over their environment that is typically only reserved for humans. ${ }^{16}$ This concept of the 'agency of the machine' exposes Ernst to charges of technological determinism, which potentially might be unfair given his acknowledgement of the close relationship between media and culture through his observation.

No study has yet been conducted into the potential benefits of cross-pollination between Ernst's brand of media archaeology and a field of media studies, such as television studies, which has a significant technical component. But some initial indications have been provided through this author's research into the early years of the Northern Irish television series, Counterpoint (1978-96). While rooted in traditional television studies, this exercise in retrospect frequently skirted the boundaries of media archaeology due to the nature of the research challenges faced, including a shortage of written archive material and a distinct lack of source material for content analysis. As a result, the study focused heavily on the recovery and analysis of technical media. The remainder of this paper seeks to discuss key themes evident within Ernst's writings through the presentation and critique of the Counterpoint project.

\section{Introducing Counterpoint}

Counterpoint was a long-running current affairs series produced by Ulster Television (UTV), a commercial broadcaster which has operated in Northern Ireland since 1959. It is affiliated with the UK's Independent Television (ITV) network. The series became renowned for its hard-hitting political coverage and its investigations into controversial social issues such as abortion, divorce and AIDS. It was also unusual in that its reach extended beyond its home region. In the mid-1980s, episodes were often screened nationally by Channel 4 while one programme 'Suffer Little Children' (06/10/1994), which examined paedophilia in the Irish Catholic Church, had major political consequences in the Irish Republic and contributed to the collapse of that state's government in November $1994 .{ }^{17}$

Despite its significance, Counterpoint has proven to be a difficult series to study due to the loss of most episodes from its first decade. For many years, only 14 of the 282 episodes made prior to January 1988 were known to exist. The earliest of these dated from November 1986. While all episodes of Counterpoint were recorded, most of the videotapes

13 Ernst, 2013a, p. 58.

14 Jussi Parikka, 'An Introduction to Wolfgang Ernst's Media Archaeology' in Wolfgang Ernst, Digital Memory and the archive, University of Minnesota

Press, 2013, p. 9.

15 Ernst, 2013a, p. 67-8

16 Parikka, 2011, p. 55.

17 'RUC warrants started an affair that brought down a government,' The Irish Times, May 25, 1995, p. 7. 
were subsequently recycled for newer programmes. To compound matters, most of the paperwork from the series remains missing, meaning that the content of many lost editions remains unclear. By 2011, UTV had identified the 268 missing editions of Counterpoint as a major gap in its archives and this author was asked to examine the possibility that some traces from these programmes could be recovered.

It was soon found that during the period involved, UTV maintained three parallel footage libraries, each of which had different retention policies. The station's videotape library was responsible for storing and managing its master programme videotapes. Meanwhile, its film library initially looked after all film footage shot for videotape programmes and the small quantity of programmes produced entirely on film. Once UTV ceased to use film in 1984, this library was responsible for handling videotape material captured using electronic newsgathering equipment. Finally, the station had a small collection of domestic videotapes which were utilised for various internal purposes and contained a mixture of UTV programmes and other material.

All these collections were examined in detail over the course of the project. Once this process was concluded, the search for missing material was extended to other archives in recognition of the series' status beyond Northern Ireland. Archives contacted included those of RTÉ, the Irish state broadcaster, the British Film Institute (BFI) and ITN, which provides ITV's national news service and frequently exchanged footage with UTV during the Northern Irish Troubles.

\section{Technology and Culture}

The initial project focus was on establishing how footage from Counterpoint was processed by each of UTV's footage libraries. While the primary aim was to locate procedural loopholes through which material may have survived destruction, this process did, in retrospect, touch upon one of Ernst's key themes - the interaction between media technology and human culture. As discussed earlier, Ernst assigns technology a level of agency typically associated with humans. He argues that this is appropriate given the existence of "the technical feedback loop" - the selfreferencing nature of technical media. This means that although such media are "messengers of other things," they are also monuments to their own existence and the technology behind it. ${ }^{18}$ Their autonomy is emphasised by the fact that they can generally only be interacted with on their own terms. For example, a videotape can only be utilised as intended using an appropriate tape recorder.

These observations raise the question of where the balance sits between mechanical and human agency. Ernst clearly prioritises the former: human agency is rarely considered in his writings and he often argues that media archaeology should not concern itself with human constructs such as culture, politics and society. He believes that the field should concentrate on studying the machine "in which the past gets archived"19 stating that "technological media, such as the radio, determine historical ways of being." ${ }^{20}$ There are various theories, which could be utilised to critique Ernst's position but the author is primarily interested in examining the insights provided by the Counterpoint project.

It was soon established that the majority of the series' missing editions were lost within the station's videotape library due to the practice of videotape recycling. This was a universal industry practice which began almost immediately after the invention of videotape in 1956. Videotape revolutionised television broadcasting: it largely eliminated the need for live broadcasts and made stations more efficient by enabling them to pre-record programmes in a manner which allowed them to make the best use of resources such as staff and studio space. Like most innovations, it had some initial teething troubles. Tape manufacturers found it difficult to produce a steady supply of blank tapes due to quality control issues. One particularly poor production run reputedly resulted in a batch of 100 tapes containing just three usable ones. ${ }^{21}$ This situation had economic consequences: an hour-long videotape cost around $\$ 300$ in the late 
1950 s, $^{22}$ prompting broadcasters to recycle their existing tapes as frequently as possible. This practice had two benefits: it ensured that broadcasters weren't caught out by tape shortages and it lowered the economic cost of the technology by allowing tape purchases to be budgeted over a large number of productions. The level of influence exercised by videotape upon its environment in this situation supports the concept of mechanical agency.

A further examination of tape recycling, however, reveals that the influence of this agency is clearly limited by human behaviour. It is apparent that there was a definite lag between the removal of the technical necessity for recycling and the actual cessation of the practice. This lag is down to the fact that recycling became an embedded part of television culture due to its value as a cost control mechanism. The role of human factors is illustrated by the varying speeds at which the practice ceased within the UK television industry, suggesting a link between recycling and organisational culture. Within the ITV network, the majority of the larger stations began to retain all major drama and entertainment programmes during the early 1970s. The one exception was ATV, which continued to wipe such programmes until its licence expired in December 1981. Meanwhile, the BBC only stopped recycling drama programme masters in 1978 after a prolonged internal debate which began around five years previously. ${ }^{23}$

Research into Counterpoint revealed that UTV was another station which had seen significant internal debate about recycling which was triggered in the late 1970s when its programme department pushed for the permanent preservation of a larger portion of its output. ${ }^{24}$

While an increasing amount of material was retained, long-running local series such as Counterpoint were routinely wiped until 1983. There then followed a transitional period where programmes could be selected for retention. Counterpoint was identified for blanket retention by its then editor Michael Beattie but the relevant hold instruction doesn't appear to have reached the videotape department, which continued to erase the series. UTV ultimately ceased wiping programmes in 1988 - a policy change which was influenced by Beattie's discovery that almost the entire run of Counterpoint had been lost. ${ }^{25}$

An examination of UTV's film holdings also supported the view that while mechanical agency does exist, it is subservient to human agency. Unlike the videotape library, UTV's film library generally retained all film footage from Counterpoint. As a result, over 150 cans of $16 \mathrm{~mm}$ film from the series were located, the majority of which consists of material shot on location. All this footage was held as separate vision and magnetic sound reels, reflecting the standard industry practice for filmed programmes in the late 1970s. An analysis of these reels, however, revealed that the station had consistently utilised non-standard sound editing methods. Magnetic sound reels would typically contain a complete soundtrack for the visual elements, marrying together the location sound with an accompanying voiceover and any additional music or sound effects. Most of the Counterpoint cans though only featured location sound as UTV, for reasons which remain unclear, did not invest in the mixing equipment necessary to produce complete soundtracks.

This meant that the station's staff had to improvise using the equipment at their disposal. According to Andrew Crockart, who directed many early editions of Counterpoint, the voiceovers and additional sounds were only added when the film was transferred to videotape for transmission purposes. He explained that this meant that "when the tape was wiped, the voiceover was lost."26 This situation only ceased in 1981 when it appears that UTV adopted industry standard editing techniques. Its long-term use of non-standard production techniques not only raises interesting questions about the extent of technical agency but has some enduring archival consequences. While film material was normally only used for location inserts on Counterpoint, occasional editions were produced entirely on film. Prior to December 1981, the accompanying soundtracks were produced on videotape and no longer exist. As a result, the only filmed editions which survive intact are 13 programmes shot between December 1981 and October 1983. 


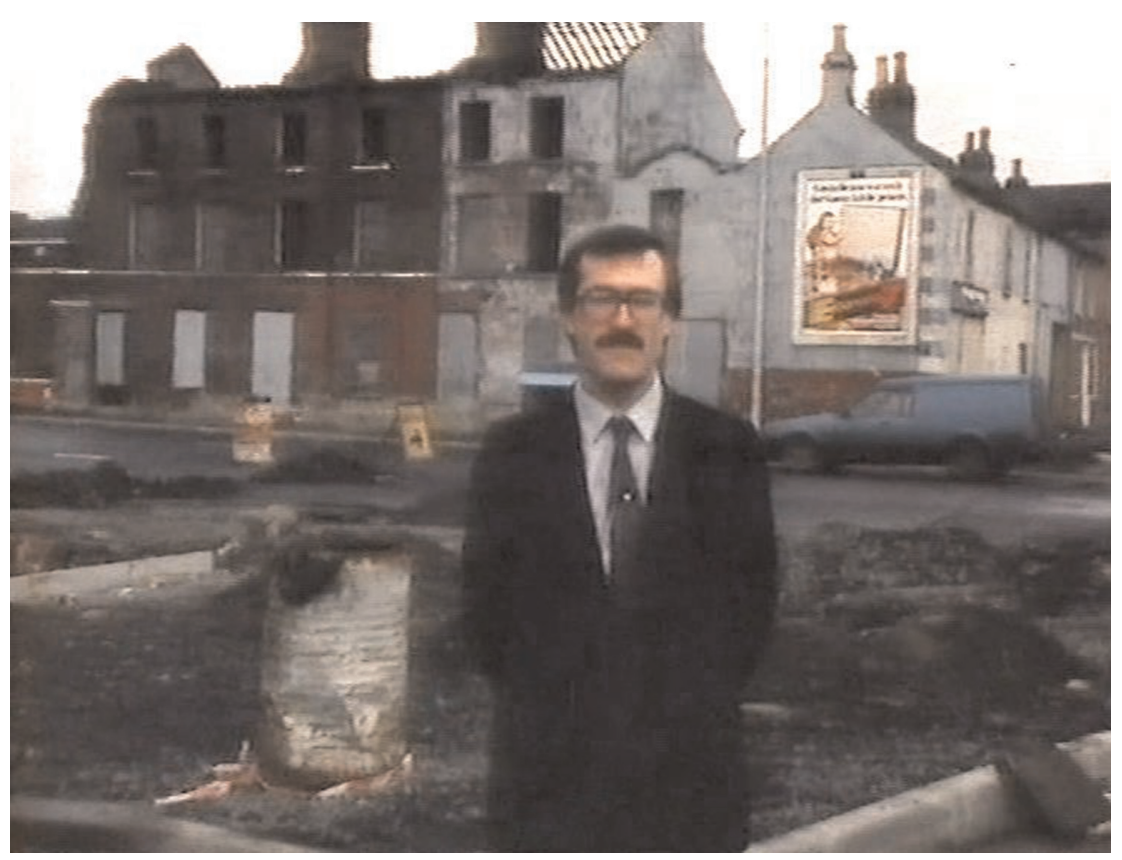

Fig. 1 Presenter Jamie Delargy in 'The Decline of Belfast' (11/02/1983), one of the 13 location-based Counterpoints shot between December 1981 and October 1983 (CUTV).

In summary, the Counterpoint project highlights the potential value of examining Ernst's conceptualisation of agency using archival research. The project provided indications that machine agency did exist but was constrained by human agency. This is clearly evident through an examination of the history of videotape recycling. In addition, it signposted issues with Ernst's argument that technology operates autonomously from culture and determines historical ways of being. This approach appears to imply that when a technical development becomes established, it is universally adopted regardless of cultural issues. The delay in the introduction of standard film sound mixing technology at UTV indicates that this isn't necessarily the case. The reason for the delay remains unclear, but it seems probable that future analysis would reveal that it was linked to organisational factors as there is no clear technical rationale for the continuing use of other techniques.

\section{Methodological Exchanges: Media Archaeography}

Further analysis of the Counterpoint project highlights the potential for methodological cross-pollination between fields such as television studies and media archaeology. In hindsight, the author's approach to UTV's videotape holdings was closely related to the concept of archaeography outlined by Ernst. At an early stage of the project, it seemed unlikely that any missing editions of Counterpoint would be located on videotape. As a result, the focus shifted to tracking down fragments and extracts from lost editions which might have survived the recycling process.

Videotapes are recycled using two main methods: taping over the original recording or by electromagnetically wiping the entire tape (degaussing). Under the first method, incomplete erasures can occur if the new recording is shorter than the tape's previous contents. This situation is often seen on domestic videotapes. While the second method should render tapes entirely blank, equipment faults or a failure to follow procedure could potentially leave a tape's contents untouched. The phenomenon of accidental survival reflects the fact that media recordings can only be manipulated by humans using technological aids. As such, they can only be destroyed through the proper use of such devices. Ernst would view this situation as rooted in the archaeographical nature of technical media whereby media act as "active archaeologists of data," preserving material which humans did not intend to capture (such as noise) or 
preserve for posterity. He suggests that the study of this inadvertently captured content may be a profitable means of examining past media. This author, who was unaware of Ernst's work at the time ${ }^{27}$ independently reached a similar conclusion.

Surviving material from UTV's domestic videotape library provided easily accessible viewing copies of the station's programmes for internal purposes from 1970 onwards. Due to their nature, these tapes were recycled on an ad-hoc basis and were never subject to the degaussing procedures used for erasing the station's master programme recordings. As such, tapes seem to have been selected for recycling on a random basis after use, which sometimes led to significant mismatches between recordings and actual tape length. This mismatch resulted in the preservation of otherwise lost material. The most extreme example located during the Counterpoint project concerned a previously lost edition, 'Violent Death On The Border' (27/11/1980), which was found on a U-Matic tape labelled as holding a drink commercial from the late-1980s. The commercial actually occupied just thirty seconds of a 60 minute tape, meaning that the entire Counterpoint programme survived with the exception of its opening titles.

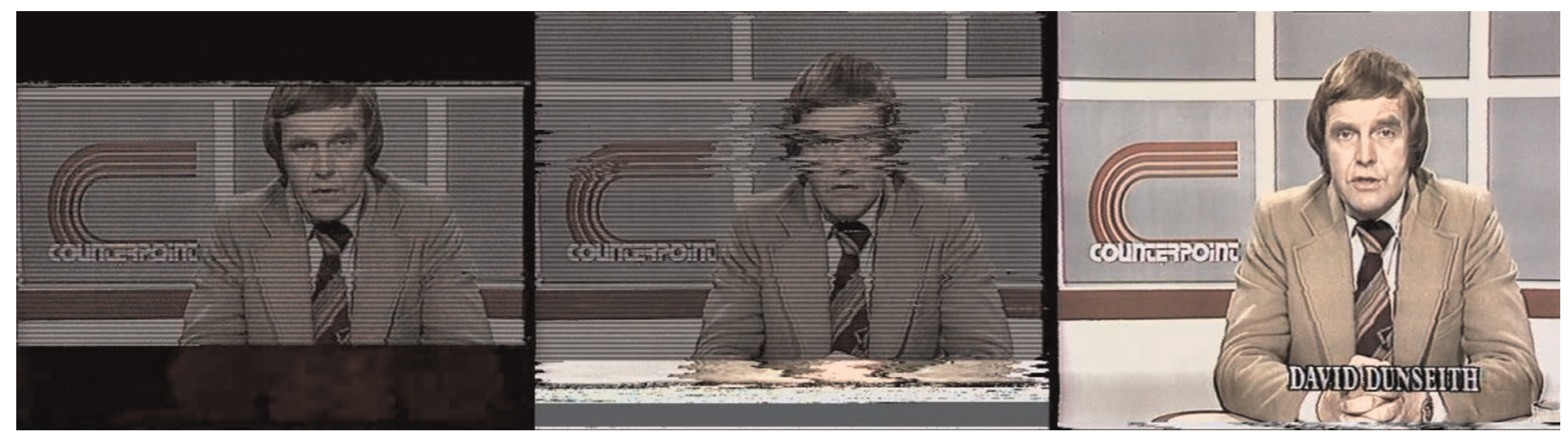

Fig. 2 Media archaeography in action: 'Violent Death On The Border' (23/11/1980) emerges from the static at the end of a drinks commercial. (OUTV).

The informal nature of domestic videotape recycling at UTV also led to the inadvertent preservation of some programmes in their entirety. The random element meant that some tapes were repeatedly reused while others were never recycled. In addition, for reasons which remain unclear, UTV tended to retain obsolete tapes even after it migrated to a more modern viewing format. As a result, this author discovered 'blank' tapes containing forgotten recordings dating back to the mid-1970s, including 17 missing editions of Counterpoint dating from 1978 to 1987.

The biggest surprises were found among the station's broadcast master videotapes, all of which should have been degaussed prior to reuse. A check of surviving masters known to have once contained wiped Counterpoint episode revealed that this procedure was not always followed. As a result, the master tapes for two editions, 'Moving Statues' (26/09/1985) and 'Travelling People' (17/09/1986), had been recycled without being degaussed. Fortunately, the new recordings on both tapes were exceptionally short, meaning that just three minutes from the start of each edition was lost. In the case of 'Travelling People,' a copy of the missing material was subsequently found on domestic videotape.

The experience of the Counterpoint project suggests that engagement with the question of media archaeography could be highly beneficial to archival television studies. In total, twenty missing editions from the series were located among unintentionally preserved videotape material. While this author retrieved this material without theoretical 
guidance, it is evident that Ernst's archaeography will form an important part of any future engagement with accidental preservation. It proves a previously absent theoretical foundation for such work and a clear expression of the nature of the material involved and its potential value as research source material. The one potentially problematic aspect of Ernst's archaeographical model is the idea that technical media can act as self-archaeologists. There seems to be little evidence to support this suggestion as technology is incapable of possessing the human drives associated with the preservation and retrieval of historical artefacts. The Counterpoint project supports though a more diluted concept of unconscious media self-archiving in respect of certain classes of material such as videotape.

\section{Methodological Exchanges: The Question of Content}

It is evident that media archaeography is potentially a useful theoretical construct within archival television studies. This raises the obvious question of whether methodologies associated with television studies might aid media archaeology. From this author's perspective, the most promising candidate is content analysis given the strong historic links between the concepts of content and the archive. The term 'archive' itself stems from the Greek arkheion, the residence of the superior magistrates where legal documents were lodged and interpreted. ${ }^{28}$ In the modern era, content provides the basis of archival catalogue systems, which allow the type of archival addressability which Ernst states is a "necessary precondition for any data retrieval. ${ }^{29}$

Throughout the Counterpoint project, archival addressability was a key challenge. In the majority of archives examined, there were evident cataloguing anomalies stemming from the misidentification of material due to issues such as poor labelling, data input errors and inconsistent cataloguing quality levels. It soon became evident that content analysis was the most efficient means of tackling this issue within the time and resources available. This process of comparing on-screen content with written catalogue data led to several significant discoveries throughout the project.

Content analysis of $16 \mathrm{~mm}$ film material held at UTV revealed that the master videotape for one pre-1986 episode of Counterpoint hadn't been recycled. The film footage held in one can matched 'A Man of Reconciliation' (20/03/1980), a programme which had been archived on videotape as an example of UTV's religious affairs output. Further research disclosed that the programme was a special edition of Counterpoint produced to mark the retirement of the then Church of Ireland Archbishop of Armagh George Simms. It was an unusual edition in that it did not feature any on-screen reference to Counterpoint, an anomaly which may have led to its identification as a standalone programme within the station's archive catalogues.

Meanwhile, the first-ever edition of Counterpoint, 'The Rape of the Shankill' (05/01/78), was located at the BFI among a collection of material donated to the institution by UTV in the early 1980s. Its significance had long been obscured by a number of cataloguing errors, which only became apparent when this author viewed the programme. ${ }^{30}$ These included a misspelt title, an inaccurate transmission date and a summary which did not refer to a crucial sequence at the start of the edition. In this sequence, the series' first editor, Derek Murray, welcomes viewers and outlines Counterpoint's goals. It is quite enlightening, as Murray explains the series wouldn't look exclusively at politics but would feature a "wide range of social concerns which affect every family in Ulster." This material represents the only known comments about the series from Murray, who died in 2006.

Further analysis revealed that only a fraction of the BFl's Counterpoint had been catalogued under the series' actual title. The remainder had been catalogued as part of The Irish Angle, the Channel 4 strand under which selected editions

28 Jacques Derrida, Archive Fever: A Freudian Impression, University of Chicago Press, 1996, p. 2-3.

29 Wolfgang Ernst, 'Dis/continuities: Does the Archive Become Metaphorical in Multi-media space?' in Wendy Chun and Thomas Keenan, eds, New Media, Old Media: A History and Theory Reader, Routledge, 2006, p. 119.

$30 \mathrm{BFI}$ database record. Available from: http://collections-search.bfi.org.uk/web/Details/ChoiceFilmWorks/150001757. (Last accessed: 20/02/2015) 


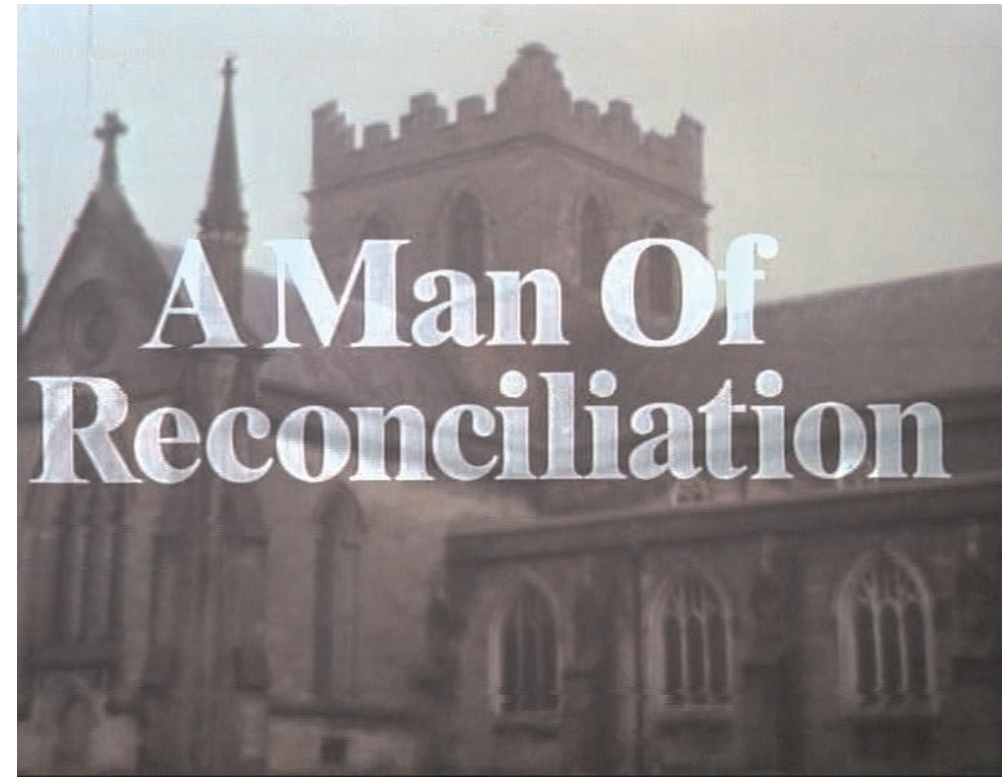

Fig. 3 The title card of 'A Man of Reconciliation' (20/03/1980), the earliest Counterpoint episode currently held on broadcast videotape at the UTV Archive (OUTV).

were aired between 1982 and 1987. These screenings were slightly edited for national screening to accommodate more advertising and to remove obscure local references. ${ }^{31}$ While UTV wiped these editions, Channel 4 retained some within its own archive and later donated them to the BFI. Unfortunately, the full extent of the BFI's holdings of Counterpoint editions remains unclear as this author was unable to view all the material it holds from The Irish Angle.

\section{Conclusion}

Despite the challenges faced, the Counterpoint project was an enormously successful research exercise. In total, fortyone missing editions from the series were found and clips were identified from around eighty of the 241 programmes which still remain lost. As noted at the outset, the research was designed as an archival project, which ended up skirting the borders of media archaeology. As a result, this piece is not designed to provide a definitive overview or critique of Ernst's writings and their implications. It is primarily concerned with discussing the potential value of cross-pollution between media archaeology and television studies based upon the experience of this author's research.

It seems evident though that some of the concepts and methodologies suggested by Ernst might prove useful in future television research. The concept of media archaeography provides a valuable theoretical grounding for the type of examination of accidental preservation undertaken within the Counterpoint project. This may encourage further engagement with the issue among television scholars who are reluctant to engage in methodologies which lack theoretical support. This is a welcome development as a wider engagement with archaeography might expand the amount of audiovisual source material available for study. The benefits also flow in the opposite direction: the type of content analysis utilised within television studies may prove helpful with media archaeology. The Counterpoint project suggests that it is highly effective in terms of placing misidentified artefacts in their appropriate historical context.

The author's research also suggests that there are potential flaws within Ernst's approach to media archaeology relating to its engagement with the real world. In some respects, Ernst's writings seem to assume simplistic models which underplay the impact of human factors on issues such as archiving. His rejection of content analysis as a media 
archaeological tool, for example, supposes a level of archival addressability that is rarely achieved within archival institutions due to resource constraints. His approach to agency appears to overstate the influence of machine agency while underplaying the potential of human agency.

In conclusion, the Counterpoint project suggests that a methodological exchange of media archaeology and television history could potentially expand the amount of source material available to scholars. It is clear, however, that certain aspects of Ernst's theories would have to be disregarded or revised to allow such a development to occur.

\section{B i o graphy}

Ken Griffin is a freelance postdoctoral researcher who specialises in regional television, media historiography and archival silences. He is currently working with Ulster University on an interstitial material preservation project which is supported by the Broadcasting Authority of Ireland. 